\title{
EFEITO DA APLICAÇÃO DE ENZIMAS PECTINOLÍTICAS NO RENDIMENTO DA EXTRAÇÃO DE POLPA DE CUPUAÇU ${ }^{1}$
}

\author{
MARIA DO SOCORRO ROCHA BASTOS², TERESA EMANUELLE PINHEIRO GURGEL ${ }^{3}$, \\ MEN DE SÁ MOREIRA DE SOUSA FILHO², INESSA DE FÁTIMA BENEVIDES LIMA³, \\ ARTHUR CLAÚDIO RODRIGUES DE SOUZA4, JOSIELE BRILHANTE SILVA ${ }^{5}$,
}

\begin{abstract}
RESUMO - O Brasil apresenta uma diversidade de frutas regionais, principalmente nas regiões Norte e Nordeste. Dentre estas, destaca-se o cupuaçu, que é uma fruta considerada exótica e de grande potencial comercial nos mercados dos estados do Sudeste do Brasil e dos países europeus. A polpa e a semente são importantes para o desenvolvimento de produtos industriais. A polpa tem sido estudada como matéria-prima para néctar; entretanto, é usada em sorvetes, geléias, purês e polpa enlatada. Atualmente, o processo de extração da polpa ainda é feito de maneira empírica, utilizando-se de acessórios como facas, colheres ou tesouras de uso doméstico, devido à forte aderência da mesma ao caroço, causando baixo rendimento no produto final. Com o objetivo de aumentar o rendimento durante o processo de extração da polpa de cupuaçu, adicionaram-se à polpa bruta dois tipos de preparações enzimáticas de ação pectolítica (Citrozym-L e Rohament PL). As concentrações estabelecidas foram de 100; 300; 500 e 750 ppm. Após todo o processo, obteve-se a polpa, e o rendimento foi comparado com a polpa-controle. O experimento foi realizado nos laboratórios de Tecnologia de Alimentos da Embrapa Agroindústria Tropical. Pelos resultados obtidos, observou-se que o rendimento da polpa com adição de Citrozym-L foi superior a 60\% nas concentrações de 300; 500 e 750 ppm, enquanto, com a utilização de Rohament-PL, o rendimento variou de 43 a 57\% nas mesmas concentrações. O rendimento da polpa-controle foi de 44 e $41 \%$, para os experimentos realizados com a primeira e segunda preparação enzimática, respectivamente. Conclui-se que a utilização de enzimas é uma alternativa para melhorar o processo de extração da polpa; adicionando-se acima de 300ppm, obtém-se um rendimento próximo a $60 \%$.
\end{abstract}

Termos para indexação: Cupuaçu, enzimas, extração

\section{EFFECT OF PECTOLYTIC ENZIMES IN THE YELD OF CUPUASSU PULP EXTRACTION}

\begin{abstract}
Brazil displays an richness fruits varieties, many of which occur in the warmer north and northeastern regions of the country. The exotic-flavored cupuassu is of particular interest for its importance on the markets in southeastern Brazil and Europe. The pul and the pits constitute industrial raw material of significant potential. As object of studies in the area of nectar production, the pulp of the cupuassu is more commonly used for manufacturing ice cream, jam, mash and canned pulp. However, the pulp and the pit adheres very tighty to each other, their separation is done manually with the aid of domestic utensils such as spoons, scissors and knives, yielding rather small amounts of pulp for further processing. In order to increase the yield during the extraction process, two commercial pectinolitic enzymes (Citrozym L and Rohament PL) in concentrations of 100, 300,500 and 750 ppm were added to the total pulp. The final yield was compared to that obtained with the control pulp (without enzymes). The experiment was carried out at the food technology laboratories at the Embrapa Tropical Agro-Industry. With the addition of the Citrozim L, the yield was over $60 \%$ at concentrations of 300, 500 and $750 \mathrm{ppm}$, while with the addition of Rohament PL the yield attained values between 43 and $57 \%$ at these same concentrations. The yield of the control sample was $44 \%$ for Citrozym L and $41 \%$ for Rohament PL. In conclusion, the use of enzymes with the purpose of increasing the yield of cupuaçu pulp during extraction is a viable alternative, and at $300 \mathrm{ppm}$ or more the yield obtained is approximately $60 \%$.
\end{abstract}

Index terms: Cupuaçu, enzymes, extraction

A fruticultura tropical é uma das atividades de maior perspectiva, notadamente para o Nordeste, uma vez que, além das condições ecológicas favoráveis nos aspectos climáticos, há também disponibilidade de áreas consideráveis, que permitem a instalação de parques industriais (Luna, 1988).

O cupuaçu (Theobroma grandifolium.) tem sua distribuição natural principalmente na região Norte, nos Estados do Amazonas e Pará. De acordo com Ducke (1993), o cupuaçu é uma planta pré-colombiana. Entretanto, a diversidade encontrada na floresta Amazônica, hoje, não é diferente.

Calzavara et al. (1984) relataram que o crescimento da utilização industrial do cupuaçu é mais concentrado em Belém-

1 (Trabalho 056/2001). Recebido: 28/02/2001. Aceito para publicação: 01/02/2002.

2 Pesquisadores -Embrapa Agroindústria Tropical - Rua Dra. Sara Mesquita , 2270- Bairro Planalto Pici - CEP: 60511-110 - Fortaleza - CE, socorro@cnpat.embrapa.br

3 Bolsistas PIBIC -CNPq- Embrapa Agroindústria Tropical

4 Assistente de Pesquisa- Embrapa Agroindústria Tropical 
PA, onde muitas indústrias produzem produtos de cupuaçu e os comercializam na Amazônia e exportam para o sul do Brasil e Europa.

Os plantios de cupuaçu têm crescido em muitas áreas da Amazônia Brasileira devido ao aumento da demanda pela polpa, que vem sendo exportada, principalmente na forma congelada, para estados do Sudeste do Brasil e para países europeus.

Barbosa et al. (1979) e Chaar (1980) analisaram a polpa de cupuaçu e os fatores de interesse na tecnologia de alimentos. Dentre os parâmetros pesquisados, os componentes voláteis do cupuaçu são o fator que eleva a atratividade do fruto. A polpa e a semente são de potencial importância para o desenvolvimento de produtos industriais. A polpa tem sido estudada como matériaprima para néctar; entretanto, é usada em sorvetes, geléias, purês e polpa enlatada.

Um dos problemas que vêm sendo enfrentados pelos produtores de cupuaçu, é o baixo rendimento na obtenção de polpas em virtude da alta viscosidade das mesmas, o que tem levado a uma taxa de retorno financeiro insatisfatória, quando comparada com o rendimento tecnológico de outros frutos.

Em produtos de frutas, as enzimas têm sido utilizadas para os seguintes propósitos: quebram as cadeias poliméricas de carboidratos, tais como pectinas, hemiceluloses e amidos, aumentando assim o rendimento do suco; melhoram o rendimento de substâncias contidas no fruto (ácidos, substâncias que conferem aroma e cor); clarificam os sucos; liqüefazem completamente o fruto, aumentando o rendimento em polpa (Yusof \& Ibrahim, 1994).

Deve-se, portanto, considerar a necessidade de estudos para levantar parâmetros técnicos de aplicação de complexos enzimáticos industriais às polpas de cupuaçu, objetivando uma melhor adequação de suas características reológicas de forma a garantir um melhor rendimento de extração dessas polpas em escala industrial.

Neste trabalho, foram utilizadas preparações enzimáticas. Uma delas é um preparado enzimático pecnolítico (Citrozym L) altamente concentrado, produzido por Aspergillus niger. O preparado contém, principalmente, pectinases, celulases e arabinases. A turbidez eventual, provocada por este preparado enzimático líquido, não tem influência alguma na atividade, nem nas características de manejo do produto. A outra enzima é uma solução aquosa que contém pectinase (Rohament-PL).

O trabalho teve como objetivo avaliar o efeito de diferentes concentrações de preparações enzimáticas, sobre o rendimento de polpa de cupuaçu.

O experimento foi conduzido em escala laboratorial, no setor de tecnologia de alimentos da Embrapa Agroindústria Tropical, em Fortaleza-CE. O Cupuaçu foi colhido nas fazendas da Embrapa Amazônia Ocidental -Manaus-AM e transportado para Fortaleza via aérea. O tempo entre a colheita e o processamento foi de, aproximadamente, 36 horas. Antes do processamento, os frutos foram selecionados e os que se encontravam completamente maduros foram separados para a realização do experimento. A polpa bruta foi retirada manualmente, acondicionada em sacos de polietileno e congelada até o momento do processamento.

Após descongelada, coletou-se a polpa bruta de forma aleatória, e pesaram-se 5 amostras de, aproximadamente, $1000 \mathrm{~g}$ de polpa bruta, sendo uma para o controle (sem enzima) e as demais para adição do preparado enzimático -Citrozym L, nas concentrações de $100 ; 300 ; 500$ e 750 ppm. O mesmo procedimento foi realizado em outra batelada para o preparado enzimático Rohament PL.

As polpas-controle e com tratamentos foram acondicionadas em sacos de polietileno de alta densidade e colocadas em banho-maria à temperatura de $30^{\circ} \mathrm{C}$, por duas horas, para ativação da enzima. Em seguida, as amostras foram novamente colocadas em banho-maria a $90^{\circ}$, por 2 minutos, com objetivo de paralisar a ação da enzima. Após as fases de tratamento com os preparados enzimáticos, o material foi despolpado em uma peneira de malha $0,3 \mathrm{~mm}$, durante uma hora, para separar a polpa do caroço. A polpa extraída foi pesada, e o rendimento obtido avaliado e comparado com a polpa-controle. Foram pesados também os caroços, os bagaços e calculadas às perdas, para que se fizesse uma relação com o rendimento.

$\mathrm{O}$ experimento foi realizado em três repetições, e os resultados obtidos foram submetidos à análise de variância, pelo software Sisvar.

As preparações enzimáticas Rohament PL e Citrozym L, utilizadas neste trabalho, e os resultados do efeito da atuação das mesmas no rendimento da polpa de Cupuaçu estão discutidos abaixo.

As Figuras 1 e 2 representam o rendimento obtido da polpa de cupuaçu, quando adicionadas concentrações de 100; 300; 500 e 750 ppm dos preparados enzimáticos Rohament PL e Citrozym L, em comparação com a polpa-controle (sem enzima). Verificou-se um aumento relevante de rendimento na variação de 44 a $64 \%$ para a 5 amostras tratadas com Citrozym L, enquanto, nas amostras tratadas com Rohament PL, o rendimento deu-se em menor escala, com variação de 41 a $57 \%$. Com esta última enzima, esperava-se que o rendimento fosse a $750 \mathrm{ppm}$; no entanto, o mesmo ocorreu com 500 ppm. Este resultado pode ser atribuído devido ao aumento da curva característica de atividade da enzima, que atingiu seu ponto máximo em que o aumento de concentração não exerce mais efeitos na atividade da mesma.

O maior rendimento obtido com a Citrozym $L$ pode ser atribuído à sua constituição, que é um composto enzimático pectinolítico altamente concentrado e produzido por Aspergillus niger, constituído principalmente por pectinases, celulases e arabinases. Estes compostos degradam os componentes de alto peso molecular da parede celular dos frutos, tais como celulose e pectina. Entretanto, a enzima Rohament PL é um composto constituído apenas de pectinase.

Nos mesmos gráficos, são mostrados os percentuais de resíduos (caroços, bagaços e outros que ficam aderidos às peneiras), onde se observa uma relação quase direta entre o rendimento e a geração de resíduos, confirmando a eficiência das enzimas na retirada da polpa que está aderida ao caroço.

Conclui-se, portanto, que as preparações enzimáticos comerciais apresentaram efeitos relevantes no aumento do rendimento da extração da polpa de cupuaçu, onde a Citrozym L mostrou maior eficiência durante o processo de extração, devido a sua constituição com pectinases, celulases e arabinases. Em relação à quantidade de resíduos gerados, principalmente bagaços e outras perdas, estes estão diretamente relacionados com as concentrações de preparados enzimáticos utilizados, isto 


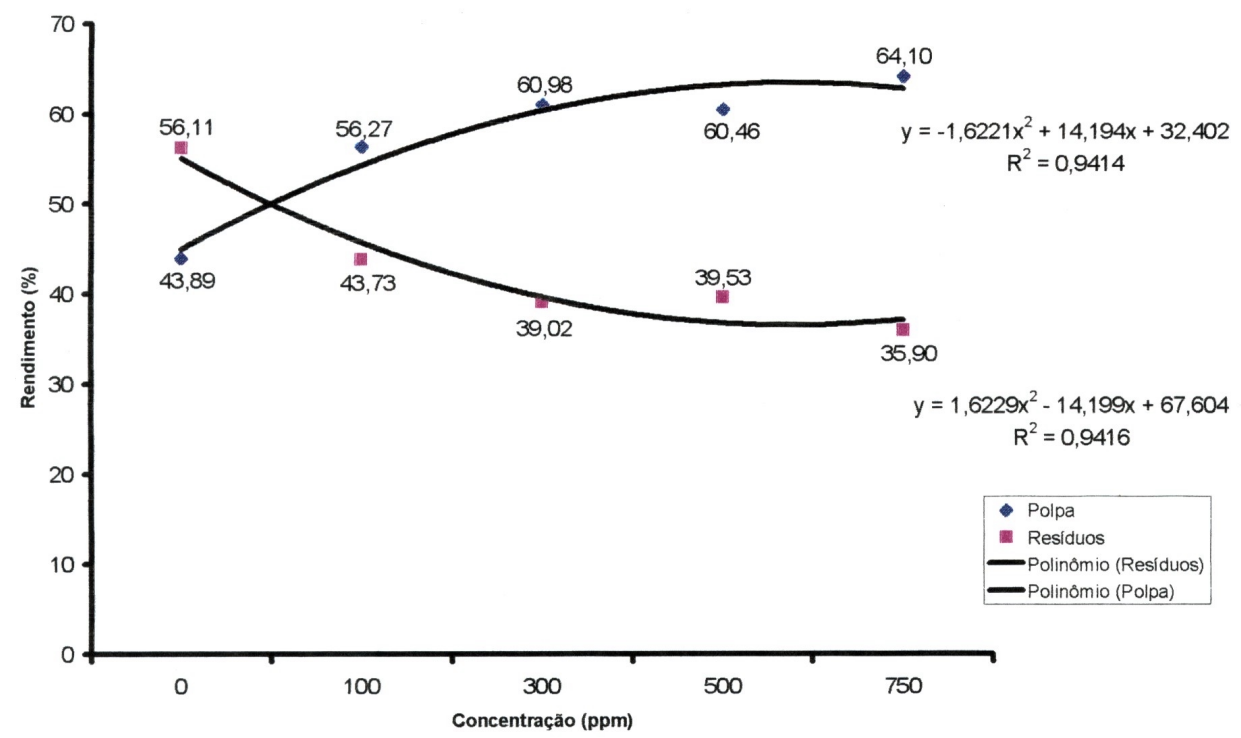

FIGURA 1- Efeito da concentração do preparado enzimático (Citrozim L) no rendimento da polpa de cupuaçu e no percentual de resíduos.

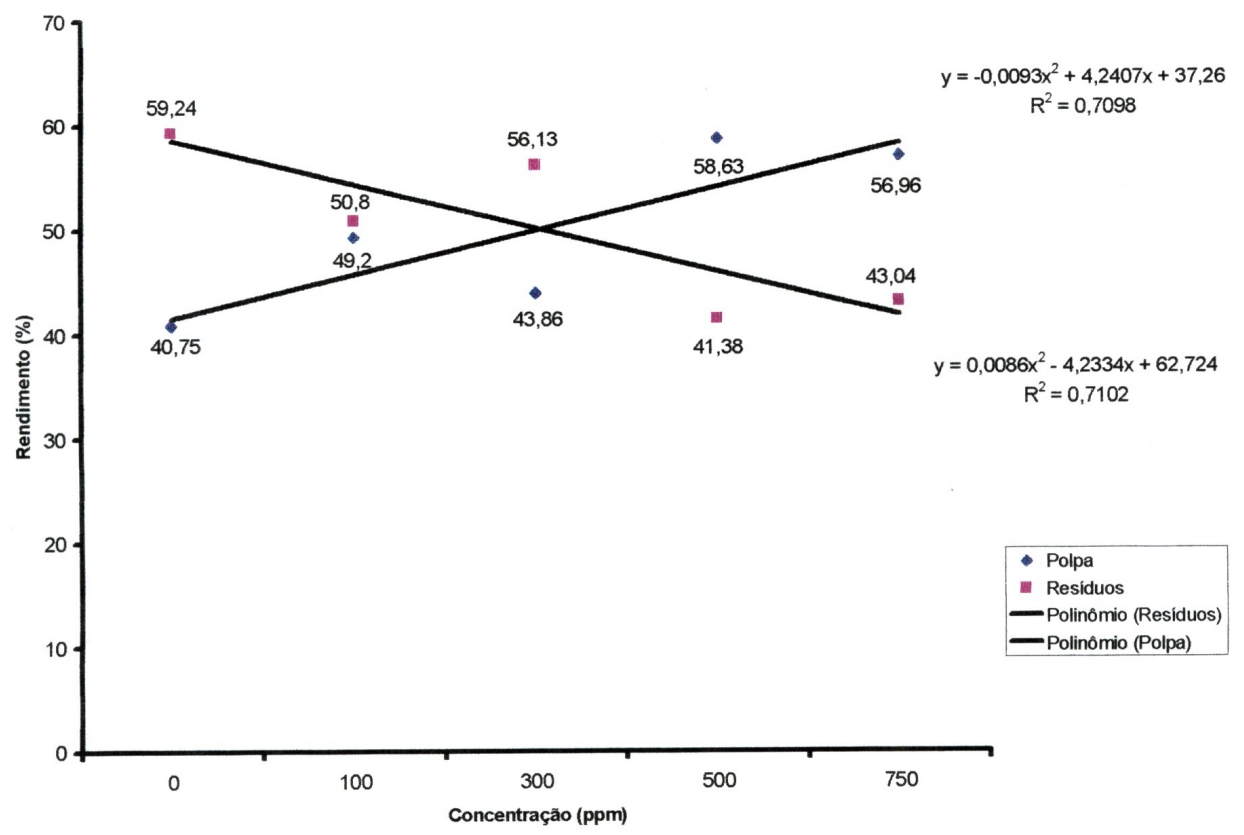

FIGURA 2 - Efeito da concentração do preparado enzimático (Rohament PL) no rendimento da polpa de cupuaçu e no percentual de resíduos.

é, quanto maior a concentração, menor a quantidade de resíduos.

\section{REFERÊNCIAS BIBLIOGRÁFICAS}

BARBOSA, W. C., DE NAZARÉ, R. F. R., NAGATA, I. Estudos físicos e químicos de frutos: bacuri (Platonia insignis), cupuaçu (Theobroma grand diflorum) e murici (Byrsonima crassifolia). In Congresso Brasileiro de Fruticultura. 5, 797-808, 1979.

CALZAVARA, B. B. G., MULLER, C. H., KAHWAGE, O. N. C. Culturas de frutos tropicais: Árvore do cupuaçu, cultivo, benefícios e utilização do fruto. EMBRAPA, CPATU, Belém, 1984.
DUCKE, A. Plants of precolombian culture in Amazônia. Bol. Tec. Inst., 26 p. 125-130, 1993.

JOSHI, V.K.; CHAUHAN, S.K; LAL, B.B. Extraction of juices from peaches, plums and apricots by pectinolytic treatment. J. Food Science Technology. V. 28, n.1, p.64-65, 1991.

SPEISER,W.Enzymes for the fruit juice Industry. Fruit Processing.p.487-489, 1986.

YUSOF, S; IBRAHIM, N. Quality of soursop juice after pectinase enzyme treatment. Food Chemistry. V.51, p.83-88, 1994. 